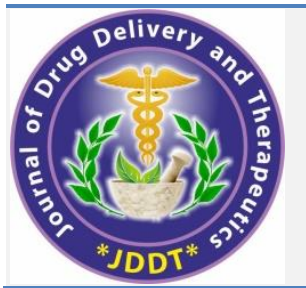

Open Access Full Text Article
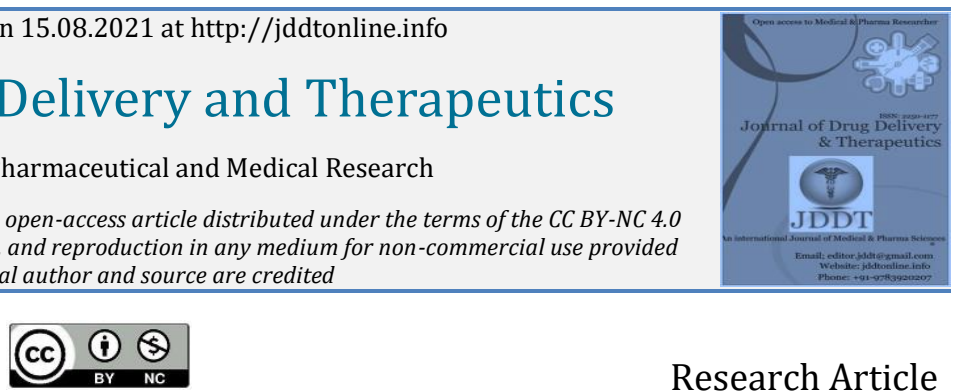

Research Article

\title{
Formulation and Evaluation of Lamivudine Nanosuspension
}

\author{
(D) Yerikala Ramesh1, (DBallem Sarayu 2, (DGuduru Hari Chandana 2, (DObili Neelima 2, (D) Shaik Sana ${ }^{2}$ \\ 1. Associate Professor, Department of Pharmaceutics, Ratnam Institute of Pharmacy, Pidathapolur (V), Muthukur (M), Nellore-524346, Andhra \\ Pradesh, India \\ 2. Ratnam Institute of Pharmacy, Pidathapolur (V), Muthukur (M), Nellore-524346, Andhra Pradesh, India
}

Article Info:

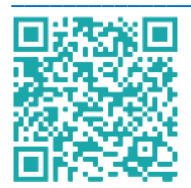

\section{Article History:}

Received 07 June 2021

Reviewed 19 July 2021

Accepted 26 July 2021

Published 15 August 2021

\section{Cite this article as:}

Ramesh Y, Sarayu B, Hari Chandana G, Neelima O, Sana S, Formulation and Evaluation of Lamivudine Nanosuspension, Journal of Drug Delivery and Therapeutics. 2021; 11(4-S):71-77

DOI: http://dx.doi.org/10.22270/jddt.v11i4-S.4961

\section{*Address for Correspondence:}

Dr. Yerikala Ramesh, M.Pharm., Ph.D., Associate Professor, Department of Pharmaceutics, Ratnam Institute of Pharmacy, Pidathapolur (V), Muthukur (M), Nellore-524346, Andhra Pradesh, India. ORCID ID: https://orcid.org/0000-0002-8331-8190

\section{Abstract}

The present research aimed to develop \& Evaluation of Lamivudine Nanosuspension. Lamivudine is a potent in vitro inhibitor of human immune deficiency virus belongs to the category of anti-retroviral drugs. The formulated Nanosuspension was subjected to various evaluation parameters like particle size, polydispersity index, zeta potential, drug content, viscosity, saturation solubility studies, In vitro release, treatment of kinetic data, and stability studies. The polydispersity ranged from 0.218 PDI to 0.331 PDI and zeta potential ranged from $-1.60 \mathrm{mV}$ to $-4.79 \mathrm{mV}$ are the important evaluation parameters are responsible for the stability of nanosuspensions. The Polydispersity index presents the quantity of particle size distribution ranges from $452.4 \mathrm{~nm}$ to $532.2 \mathrm{~nm}$. In this result, LNSF4 shows spectacular drug content range of $86 \pm 1.8 \%$ to $97 \pm 2.5 \%$ it is the maximum drug content. The Brook field viscometer to determine the viscosity of Lamivudine Nano suspension of different formulations was found to be $44.4 \pm 2.1$ cps to $87.7 \pm 1.4 \mathrm{cps}$. The general Nanosuspension formulations LNSF4 shows $98.64 \%$ better controlled released in comparison with abundant formulation. In all the cases the best-fit model encounter uoto be peppas with ' $n$ ' value between 0.768 to 0.917 . The ' $n$ ' value of formulation LNSF4 was 0.876 and suggesting so the drug was released by Zero-order kinetics. Acceleration stability studies intermediate storage condition has been changed from $30^{\circ} \mathrm{C} \pm 2^{\circ} \mathrm{C}$ and $60 \% \mathrm{RH} \pm 5 \%$ Relative Humidity. After a 90 days study it revolves that there's no change in Drug content, In vitro drug release, and particle size.

Keywords: Lamivudine, Nanosuspension, Saturation solubility, Scanning Electron Microscopy, Stability study.

\section{INTRODUCTION:}

Nanosuspension is defined as a sub-micron colloidal system it's contains the poorly soluble drug, waver in a suitable dispersion medium stabilised by the surfactants. Nanosuspension usually consists of colloidal carriers like polymeric resins which are inert 1 . They help in the enhancement of drug solubility and thus bioavailability. Unlike microemulsions, there is no irritant in nature. Nanosuspension also imparts stability of your drug within the formulation. Nanosuspension can be prepared by different methods such as high-pressure homogenization and media milling. Lamivudine has been formulated in many formulations but they do not overcome the main limitations like therapeutic effectiveness of Lamivudine 2 its dose-dependent toxicity, short biological half-life, and poor bioavailability, effectively so were developed the nanosuspension in high-pressure homogenizer technique. An effort has to conquer the problem with prepared Nanosuspension. The main objectives involved in the study are to extend the dose of medication of the drug to increase the rate plus extent of absorption of the drug to enhance the effectiveness in therapy.

\section{MATERIALS AND METHODS:}

Lamivudine was obtained as a gift sample from Hetero Pharmaceutical PVT Limited, Hyderabad, HPMC K-30, Eudragit S 100, Tween-80, PVP K-30, Poloxamer 188, Methanol was purchased from Himalaya pharmaceutical, Nellore and other ingredients used were of Analytical grade.

\section{METHODOLOGY}

\section{Drug and excipients interaction (FTIR)}

The compatibility between pure drug and polymers like HPMC K-30, PVP K-30, poloxamer-188, Eudragit S100 were detected by FTIR spectroscopy (Bruker Pvt. Ltd, Germany). The finely grounded powder was introduced into stainless steel die ${ }^{3}$. The powder was pressed in the die between polished steel anvils at a pressure of about 10t/in2. For liquid samples, a thin film of sample liquid is made on a pellet.

\section{Preparation method of Nanosuspension}

The drug used to be molten in methanol to prepare an organic solution and fixed Amount (Table 1). The polymers and surfactant are dissolved in a mentioned quantity of water it is the aqueous phase. The aqueous water is kept under a high-pressure homogenizer (Remi RQ- 127) at 
room temperature. The organic solution is added drop-wise through a syringe to the aqueous solution. Under process of high-pressure homogenizer at a rotation speed of $100 \mathrm{Rpm}$ up to 8 hours ${ }^{4}$. Nanosuspension was formed, Spectacular organic solution used to be gaseous at temperature (Table 1).

Table 1: Formulation of Lamivudine Oral nanosuspension

\begin{tabular}{|l|l|l|l|l|l|l|}
\hline Ingredient & LNSF1 & LNSF2 & LNSF3 & LNSF4 & LNSF5 & LNSF6 \\
\hline Lamivudine & $5 \mathrm{gm}$ & $5 \mathrm{gm}$ & $5 \mathrm{gm}$ & $5 \mathrm{gm}$ & $5 \mathrm{gm}$ & $5 \mathrm{gm}$ \\
\hline Poloxomer- 188 & - & - & $150 \mathrm{mg}$ & $1500 \mathrm{mg}$ & - & - \\
\hline HPMC k-30 & $150 \mathrm{mg}$ & $1500 \mathrm{mg}$ & & & - & - \\
\hline Eudragit S 100 & - & - & - & - & $150 \mathrm{mg}$ & $1500 \mathrm{mg}$ \\
\hline PVP k-30 & $3 \mathrm{gm}$ & $3 \mathrm{gm}$ & $3 \mathrm{gm}$ & $3 \mathrm{gm}$ & $3 \mathrm{gm}$ & $3 \mathrm{gm}$ \\
\hline Tween-80 & $1 \mathrm{ml}$ & $1 \mathrm{ml}$ & $1 \mathrm{ml}$ & $1 \mathrm{ml}$ & $1 \mathrm{ml}$ & $1 \mathrm{ml}$ \\
\hline Methanol & $60 \mathrm{ml}$ & $60 \mathrm{ml}$ & $60 \mathrm{ml}$ & $60 \mathrm{ml}$ & $60 \mathrm{ml}$ & $60 \mathrm{ml}$ \\
\hline Water & $100 \mathrm{ml}$ & $100 \mathrm{ml}$ & $100 \mathrm{ml}$ & $100 \mathrm{ml}$ & $100 \mathrm{ml}$ & $100 \mathrm{ml}$ \\
\hline
\end{tabular}

\section{Evaluation parameters}

\section{Scanning Electron Microscopy}

The surface geomorphology of the freeze-dried nanosuspension used to be planned using SEM 5 .

\section{Particle size, polydispersity index measurement Zeta potential:}

The particle size and its distribution were determined using Zetasizer Nano ZS using a process called Dynamic Light Scattering. The zeta potential of a particle is the overall charge that the particle acquires in a particular medium ${ }^{6}$.

\section{Drug content}

$0.5 \mathrm{ml}$ of each one preparation was utilized for dissolve in $10 \mathrm{ml}$ isotonic solution and kept overnight and also $10 \mathrm{mg}$ of your drug were utilized for melted in ten $\mathrm{ml}$ of the isotonic solution and kept overnight 7 . From that, all preparations along with the drug were filtered dilutions made in the put concentration of one microgram per millimetre. These dilutions were estimated their content uniformity by reason a UV spectrophotometer at the wavelength $271 \mathrm{~nm}$.

\section{Viscosity}

The Nano suspension was performed by using the Brookfield viscometer set the spindle No - 60 at 100rpm ${ }^{8}$.

\section{Saturation Solubility Studies}

The saturation solubility studies were done on both the unprocessed pure drug and different batches of the lyophilized Lamivudine Nanosuspension. By the way for 10 mg of the unprocessed pure drug compound and Nanosuspension equivalent to $10 \mathrm{mg}$ were weighed and measured separately and introduced into a $25 \mathrm{ml}$ Stoppard conical flask Containing $10 \mathrm{ml}$ distilled water. The flasks were sealed and placed in a rotary shaker for $24 \mathrm{hrs}$ at room temperature and equilibrated for 2 days ${ }^{9}$. The diluted samples were analyzed using a UV spectrophotometer at $271 \mathrm{~nm}$.

\section{In vitro release study}

The entire formulations by the way of utilizing the USP category II dissolution equipment, Dissolution medium $900 \mathrm{ml}$ of $0.1 \mathrm{~N}$ HCL rotating speed is $50 \mathrm{rpm}$ Temperature kept constant at $37 \pm 0.5^{\circ} \mathrm{C}$ sampling withdrawing time is followed 1 to 8 hours at programmed time interval aliquot samples $(5 \mathrm{ml})$ were collected and replenished by the same quantity of fresh medium ${ }^{10}$. The aliquot sample $(5 \mathrm{ml})$ was filtered using the supporter of $0.45 \mu \mathrm{m}$ restricted membrane filter paper and the filtrate was to be diluted properly through the fresh medium and was predictable using UV-Vis spectrophotometer (model UV-2600plus) at wavelength $271 \mathrm{~nm}$.

\section{Treatment of dissolution data with a different kinetic model}

The amount of drug released from Lamivudine Nanosuspension was analyzed by the way of the total value of point in time must be performed with a flexible model. For finding out the mechanism of drug release from the Lamivudine Nanosuspension, the dissolution data obtained from the above experiments were treated with the following different release kinetic models ${ }^{11}$.

Zero order- Q=Ko $\mathrm{t}$

First order- $\log \mathrm{Q}=\log \mathrm{Qo}-\mathrm{K} 1 \mathrm{t} / 2.303$.

Higuchi- Qt $=$ KH t $1 / 2$

Korsmeyer - Peppas- Qt/Q $\alpha=K$ tn

A plot of $\log$ (drug release) versus log t will be linear with a slope of $\mathrm{n}$ and the intercept gives the value of $\log \mathrm{k}$ as shown in Table 2.

To study the release kinetics, data obtained from in vitro drug release studies were plotted as log cumulative percentage drug release vs. log time.

Table 2: Diffusion exponent values indicating drug release mechanism

\begin{tabular}{|l|l|l|}
\hline S.No. & $\begin{array}{l}\text { Diffusion exponent } \\
\text { value }(\mathrm{n})\end{array}$ & $\begin{array}{l}\text { Drug release } \\
\text { mechanism }\end{array}$ \\
\hline 1 & $<0.45$ & Fickian release \\
\hline 2 & 0.45 to 0.89 & non-Fickian transport \\
\hline 3 & 0.89 & Case II transport \\
\hline 4 & $>0.89$ & Super case II transport \\
\hline
\end{tabular}

\section{Stability Study of Nanosuspension}

The stability studies for Nanosuspension have performed storage conditions for 90 days as follows Acceleration stability studies intermediate storage condition has been changed from $30^{\circ} \mathrm{C} \pm 2{ }^{\circ} \mathrm{C}$ and $60 \% \mathrm{RH} \pm 5 \% \mathrm{RH}$. The optimized batch LNSF4 Nanosuspension was utilized for each condition; the particle size, Drug content, and In-vitro dissolution are the most vital specification for the activity \& physical stability 16 . 


\section{RESULT AND DISCUSSION}

\section{PREFORMULATION STUDIES}

\section{Drug and excipients interaction study}

Drug polymer compatibility studies were performed by the FTIR method. The spectra of Lamivudine, HPMC K30, PVP
K-30, poloxamer- 188, and Eudragit S100 alone and prepared formulations of drug with the above polymers were measured and interpreted. The IR spectra were depicted as Figures 1 to 6 and interpreted values are tabulated in Table. 3. The IR spectra of drug and polymer alone and prepared formulations show no significant interaction between drug and polymer.

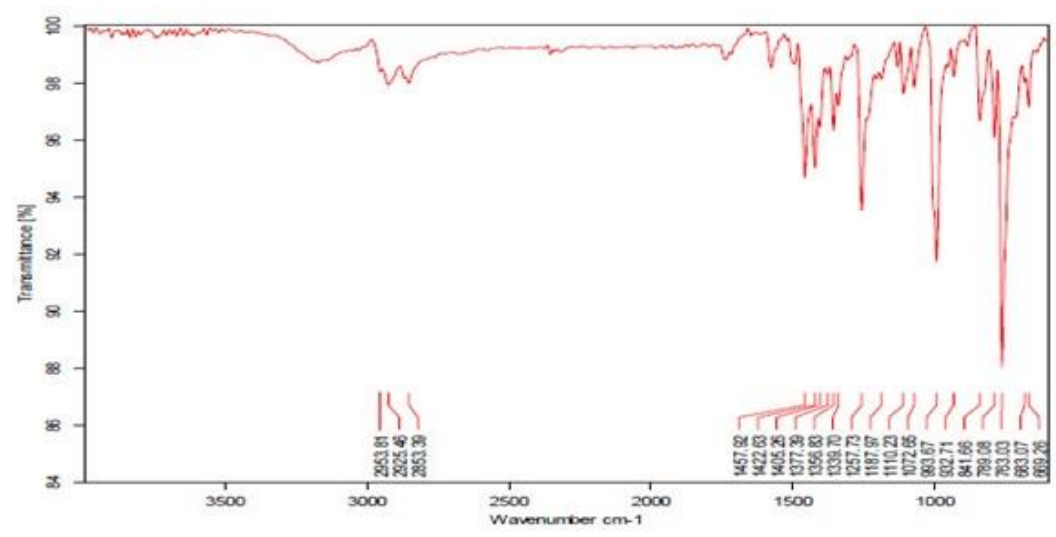

Figure 1: FTIR Spectrum of Lamivudine

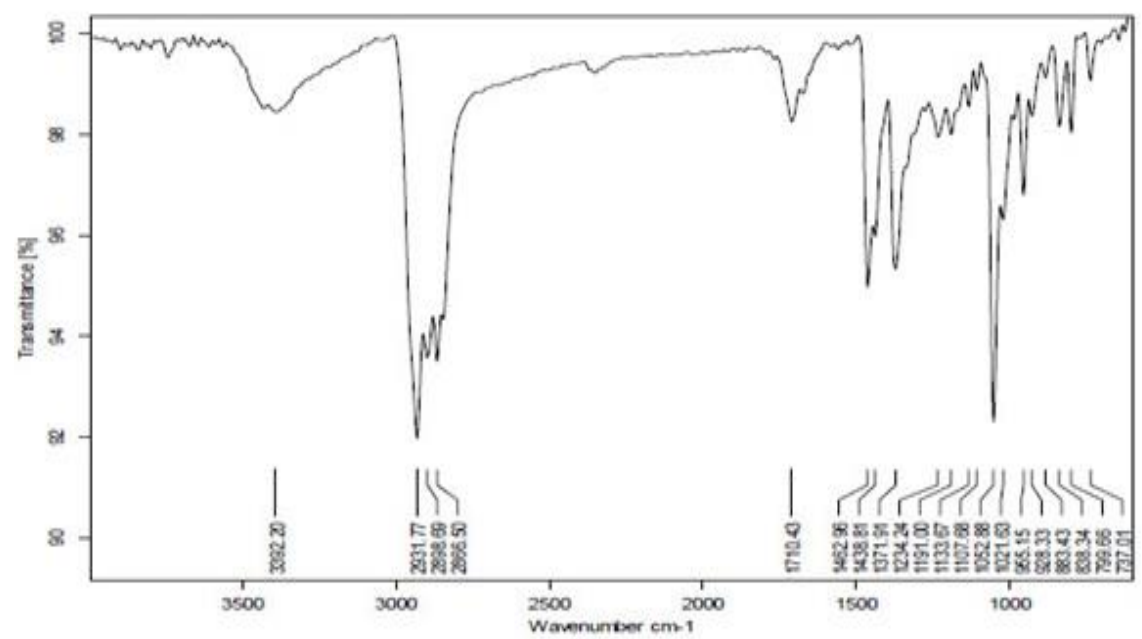

Figure 2: FTIR Spectrum of Poloxamer 188

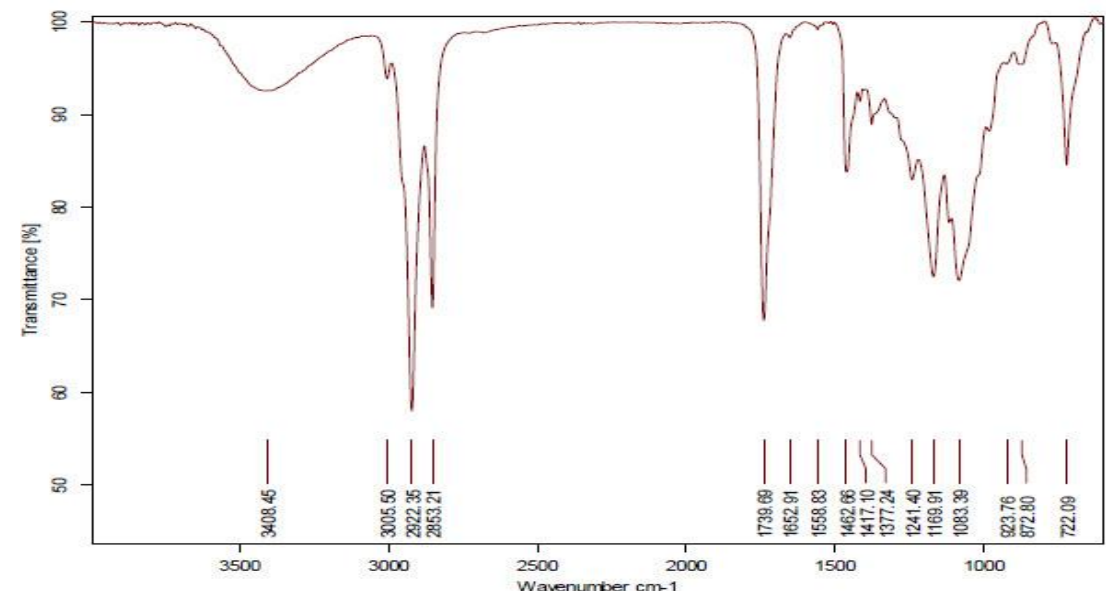

Figure 3: FTIR Spectrum of Eudragit S 100 


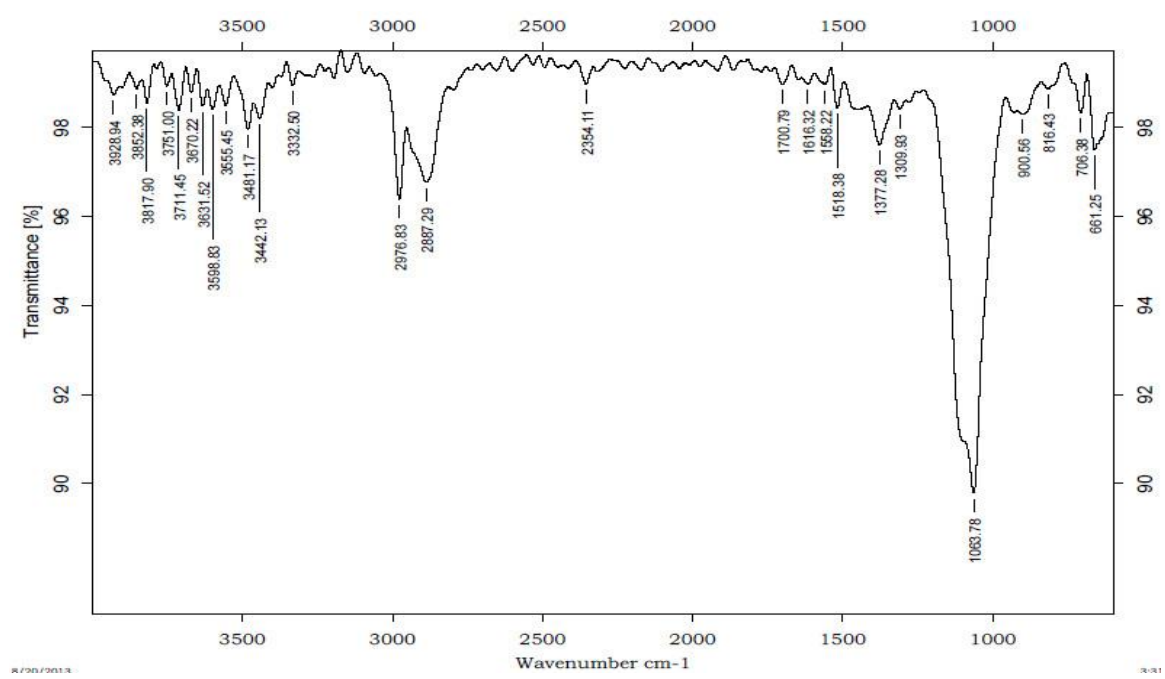

Figure 4: FTIR spectra of HPMC K 100

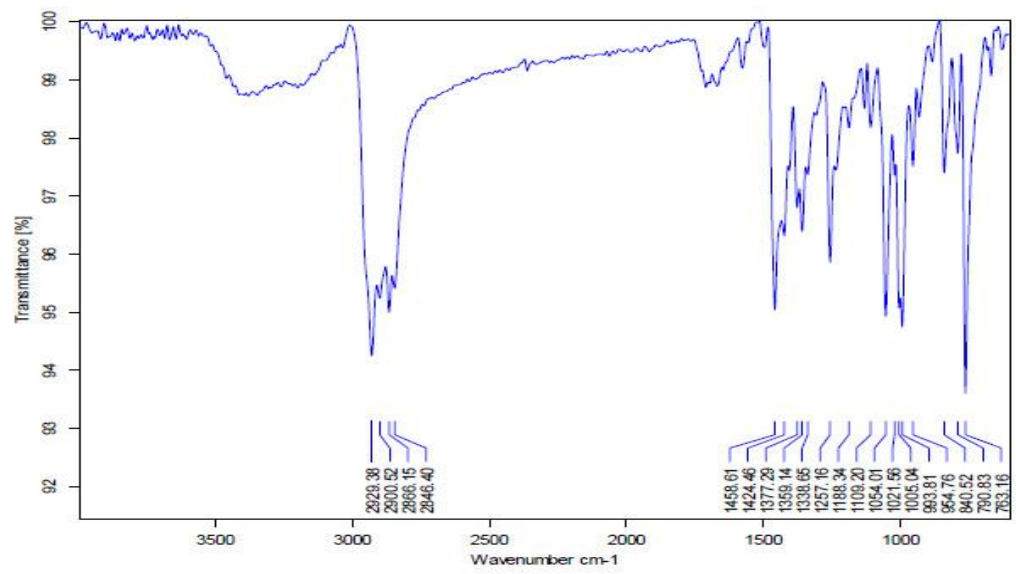

Figure 5: FTIR spectra of PVP K30

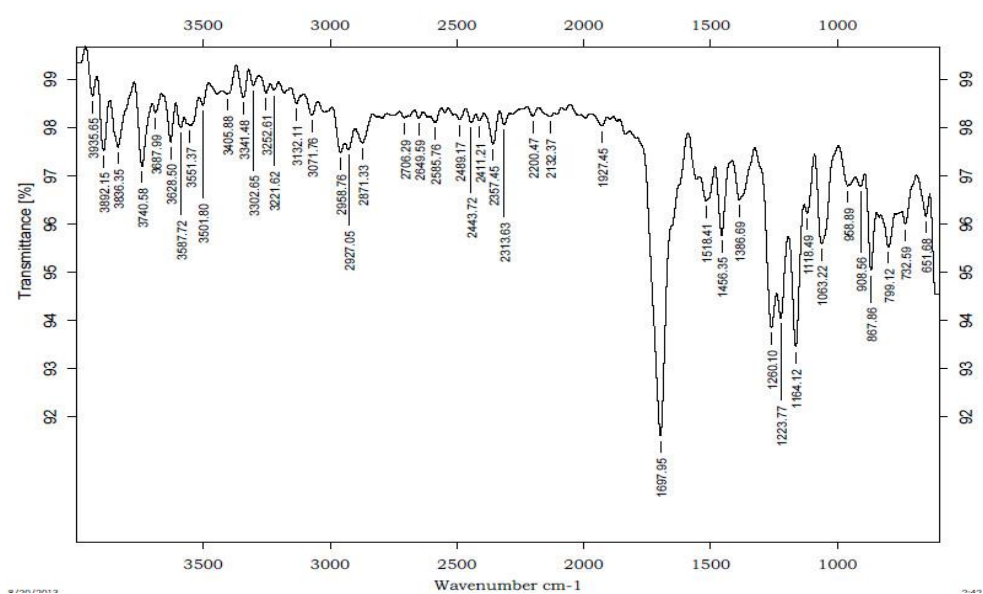

Figure 6: FTIR Spectrum of Lamivudine + Poloxamer + Eudragit + PVP K30 \& Tween 80

Table 3: FTIR Spectrum Interpretation obtained for drug along with excipients

\begin{tabular}{|l|l|l|l|l|l|l|l|}
\hline $\begin{array}{l}\text { Functional } \\
\text { Group }\end{array}$ & $\begin{array}{l}\text { Literature } \\
\text { Value }\end{array}$ & Pure Drug & $\begin{array}{l}\text { Poloxamer } \\
\mathbf{1 8 8}\end{array}$ & $\begin{array}{l}\text { Eudragit S } \\
\mathbf{1 0 0}\end{array}$ & HPMC K 100 & PVP K30 & Mixture \\
\hline N-H stretch & $3500-3180$ & 3171.36 & 3392.20 & 3408.45 & 3711.45 & 3740.58 & 2929.38 \\
\hline Alkyl C-H Stretch & $2950-2850$ & 2868.62 & 2868.62 & 2922.35 & 2887.29 & 2927.05 & 2929.38 \\
\hline C=O stretch & $1810-1775$ & 1714.21 & 1710.43 & 1739.69 & 1700.79 & 1697.95 & 1658.61 \\
\hline C-H bend (para) & $850-800$ & 840.62 & 883.45 & 872.80 & 816.43 & 867.86 & 840.52 \\
\hline
\end{tabular}




\section{Scanning Electron Microscopy (SEM)}

The shape and surface morphology of freeze-dried optimized nanosuspension (LNSF4) was observed by the SEM. The SEM images of optimized Nanosuspension at $2000 \times$ Magnification LNSF4 show a $20 \mu \mathrm{m}$ spherical shape of Nanosuspension as shown in figure 7.

Particle size, poly dispersivity index measurement Zeta potential

The polydispersity ranged from 0.218 PDI to 0.331 PDI and zeta potential ranged from $-1.60 \mathrm{mV}$ to $-4.79 \mathrm{mV}$. The particulate distribution ranges from $452.4 \mathrm{~nm}$ to $532.2 \mathrm{~nm}$ as shown in Table 4.

\section{Drug content}

In this result LNSF4 ranges from $86 \pm 1.8 \%$ to $97 \pm 2.5 \%$ it is the maximum drug content (Table 4).

\section{Viscosity}

The Lamivudine Nanosuspension of different formulations was found to be $44.4 \pm 2.1$ cps to $87.7 \pm 1.4 \mathrm{cps}$ and as shown in table 4 . They show the result within satisfactory limits.

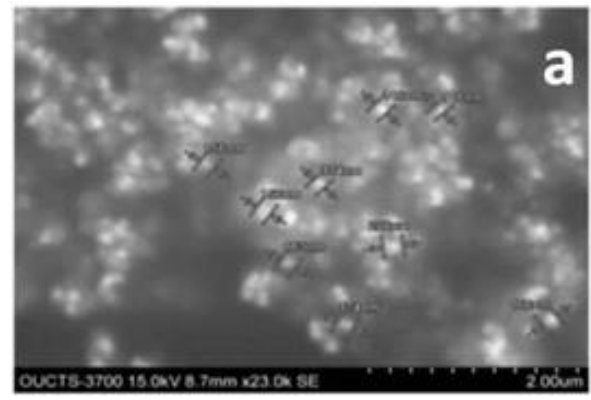

Figure 7: Scanning Electron microscopy image of optimized formulation

Table 4: Particle size and zeta potential of Lamivudine nanosuspensions

\begin{tabular}{|l|l|l|l|l|l|}
\hline Formulation & Particle size (nm) & PDI & ZP (mV) & Drug content (\%) & Viscosity (cps) \\
\hline LNSF1 & 523.2 & 0.293 & -1.60 & $95 \pm 1.3$ & $44.4 \pm 2.1$ \\
\hline LNSF2 & 435.2 & 0.218 & -2.93 & $94 \pm 2.6$ & $47.3 \pm 1.3$ \\
\hline LNSF3 & 364.9 & 0.288 & -2.79 & $92 \pm 2.8$ & $54.5 \pm 1.2$ \\
\hline LNSF4 & 532.2 & 0.283 & -4.79 & $97 \pm 2.5$ & $87.7 \pm 1.4$ \\
\hline LNSF5 & 342.0 & 0.278 & -3.26 & $86 \pm 1.8$ & $64.9 \pm 3.8$ \\
\hline LNSF6 & 452.4 & 0.331 & -4.10 & $89 \pm 1.7$ & $67.2 \pm 13$ \\
\hline
\end{tabular}

\section{Saturation Solubility}

This is due to the decrease in particle size when compared to pure dug according to the Ostwald-Freundlich equation. The fold increase in the solubility of the drug is depicted in Table 5 .

Table 5: Saturation Solubility of pure drug

\begin{tabular}{|l|l|l|l|l|l|l|}
\hline \multirow{2}{*}{ Medium } & \multicolumn{5}{|c|}{ Pure drug concentration (Mean SD) } \\
\cline { 2 - 7 } & LNSF1 & LNSF2 & LNSF3 & LNSF4 & LNSF5 & LNSF6 \\
\hline Distilled water & $2.90 \pm 0.53$ & $1.50 \pm 0.43$ & $3.50 \pm 0.23$ & $2.50 \pm 0.13$ & $1.60 \pm 0.42$ & $2.40 \pm 0.62$ \\
\hline pH 1.2 buffer + 2.2\% w/v SLS & $3223 \pm 25.12$ & $2836 \pm 30.43$ & $2234 \pm 29.61$ & $2435 \pm 23.47$ & $2653 \pm 21.56$ & $2826 \pm 45.18$ \\
\hline Phosphate buffer pH 7.4 & $3.52 \pm 1.22$ & $2.22 \pm 1.32$ & $2.42 \pm 1.41$ & $3.25 \pm 1.83$ & $2.31 \pm 1.43$ & $3.24 \pm 1.54$ \\
\hline $2.2 \%$ w/v SLS in water & $3910 \pm 31.40$ & $3420 \pm 32.50$ & $3430 \pm 33.30$ & $2630 \pm 28.10$ & $2840 \pm 30.50$ & $3989 \pm 30.30$ \\
\hline
\end{tabular}

\section{In-vitro Drug Release Studies}

The dissolution kinetic profiles of nanosuspension formulations, LNSF4 shows $98.64 \%$ better controlled released compared to other formulations (Tables 6 \& Figures 8).

Table 6: In-vitro drug release of Lamivudine Nanosuspension

\begin{tabular}{|l|l|l|l|l|l|l|}
\hline \multirow{2}{*}{$\begin{array}{l}\text { Time } \\
(H r s)\end{array}$} & \multicolumn{7}{|c|}{ \% Drug Release } \\
\cline { 2 - 7 } & LNSF 1 & LNSF 2 & LNSF 3 & LNSF 4 & LNSF 5 & LNSF 6 \\
\hline 0 & 0 & 0 & 0 & 0 & 0 & 0 \\
\hline 1 & 10.00 & 12.12 & 23.51 & 12.21 & 13.63 & 12.82 \\
\hline 2 & 25.32 & 29.62 & 32.38 & 21.62 & 22.84 & 22.47 \\
\hline 3 & 36.83 & 42.73 & 42.57 & 30.38 & 39.29 & 32.61 \\
\hline 4 & 48.02 & 53.62 & 51.41 & 49.92 & 47.21 & 53.04 \\
\hline 5 & 57.52 & 62.81 & 60.83 & 62.26 & 56.05 & 64.07 \\
\hline 6 & 71.27 & 73.01 & 70.46 & 71.43 & 75.02 & 73.92 \\
\hline 7 & 83.45 & 84.07 & 82.00 & 82.73 & 84.26 & 81.05 \\
\hline 8 & 96.03 & 97.12 & 90.75 & 98.64 & 92.01 & 94.53 \\
\hline
\end{tabular}




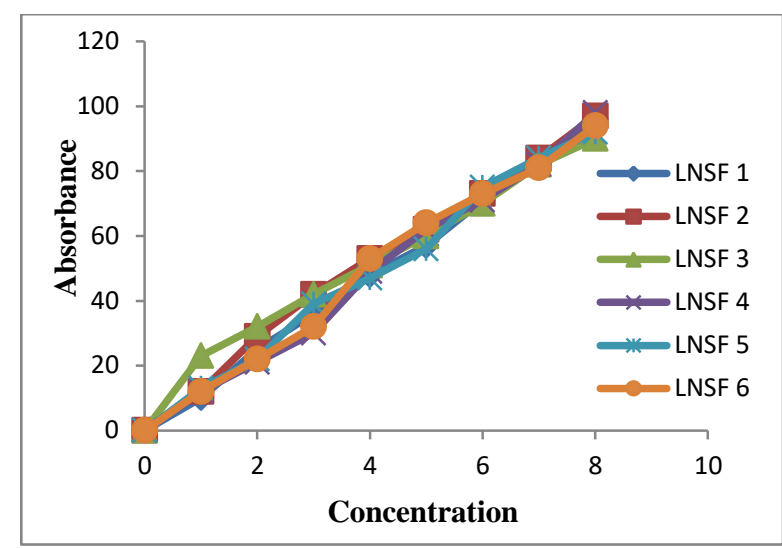

Figure 8: In-vitro drug release Profiles of Formulations LNSF 1- LNSF 6

\section{Release kinetics}

The kinetic versions chosen were Zero order, First order, Higuchi Matrix, and Korsemayer Peppas best formulation LNSF4. The regression coefficient values for all these models.
In all the cases the best-fit model was found to be peppas with ' $n$ ' value between 0.768 to 0.917 . The ' $n$ ' value of formulation LNSF4 was 0.876 and suggesting that the drug was released by Zero-order kinetics as shown in Table 7.

Table 7: Release Order Kinetics for formulation LNSF1 to LNSF6

\begin{tabular}{|l|l|l|l|l|l|}
\hline \multirow{2}{*}{ Formulation code } & Zero order $\left(\mathbf{r}^{2}\right)$ & First order $\left(\mathbf{r}^{2}\right)$ & Higuchi model $\left(\mathbf{r}^{2}\right)$ & \multicolumn{2}{|c|}{ Korsmeyer-Peppas model } \\
\cline { 4 - 6 } & & & & $\left(\mathbf{r}^{2}\right)$ & $\mathbf{n}$ \\
\hline LNSF1 & 0.984 & 0.773 & 0.962 & 0.988 & 0.781 \\
\hline LNSF2 & 0.964 & 0.842 & 0.984 & 0.993 & 0.794 \\
\hline LNSF3 & 0.985 & 0.858 & 0.958 & 0.983 & 0.768 \\
\hline LNSF4 & 0.994 & 0.998 & 0.896 & 0.996 & 0.876 \\
\hline LNSF5 & 0.980 & 0.885 & 0.964 & 0.978 & 0.892 \\
\hline LNSF6 & 0.986 & 0.834 & 0.961 & 0.98 & 0.793 \\
\hline
\end{tabular}

\section{Stability studies}

Stability studies are done for best formulation (LNSF4) as per ICH guideline as follows Acceleration stability studies intermediate storage condition has been changed from $30^{\circ} \mathrm{C}$ $\pm 2{ }^{\circ} \mathrm{C}$ and $60 \% \mathrm{RH} \pm 5 \% \mathrm{RH}$. It focuses that there's no change in Drug content, In vitro drug release, and particle size but it was within the acceptable limit as shown in Table 8 \& 9 \& Figure 9.
Table 8: Stability study for formulation LNSF4 in Acceleration stability studies

\begin{tabular}{|c|c|c|}
\hline \multirow{2}{*}{ Period } & \multicolumn{2}{|c|}{$\begin{array}{r}\mathbf{3 0}^{\circ} \mathbf{C} \pm \mathbf{2}^{\circ} \mathbf{C} \text { and } \\
\mathbf{6 0 \%} \mathbf{~} \mathbf{H} \mathbf{5 \%} \mathbf{~ R H}\end{array}$} \\
\cline { 2 - 3 } & \% Drug content & Particle size \\
\hline 15 Days & $98 \pm 1.4$ & 542.1 \\
\hline 30 Days & $98 \pm 1.9$ & 543.0 \\
\hline 60 Days & $98 \pm 2.1$ & 544.2 \\
\hline 90 Days & $98 \pm 2.4$ & 546.3 \\
\hline
\end{tabular}

Table 9: In vitro studies of formulation LNSF4 Acceleration stability studies

\begin{tabular}{|l|l|l|l|l|}
\hline \multirow{2}{*}{ Time in hrs } & \multicolumn{4}{|c|}{$\begin{array}{c}\text { Cumulative percentage drug release } \\
\mathbf{3 0}{ }^{\circ} \mathbf{C} \pm \mathbf{2}^{\circ} \mathbf{C} \text { and } \mathbf{6 0} \mathbf{R H} \pm \mathbf{5 \%} \mathbf{~ R H}\end{array}$} \\
\cline { 2 - 5 } & $\mathbf{1 5}$ Days & $\mathbf{3 0}$ Days & $\mathbf{6 0}$ Days & $\mathbf{9 0}$ Days \\
\hline 1 & 12.21 & 12.24 & 13.24 & 14.24 \\
\hline 2 & 21.62 & 21.73 & 22.73 & 24.73 \\
\hline 3 & 30.38 & 30.40 & 31.40 & 33.40 \\
\hline 4 & 49.92 & 49.94 & 50.94 & 53.94 \\
\hline 5 & 62.26 & 62.29 & 64.29 & 66.29 \\
\hline 6 & 71.43 & 71.48 & 73.48 & 77.48 \\
\hline 7 & 82.73 & 82.78 & 83.78 & 86.78 \\
\hline 8 & 98.64 & 98.68 & 98.70 & 99.70 \\
\hline
\end{tabular}




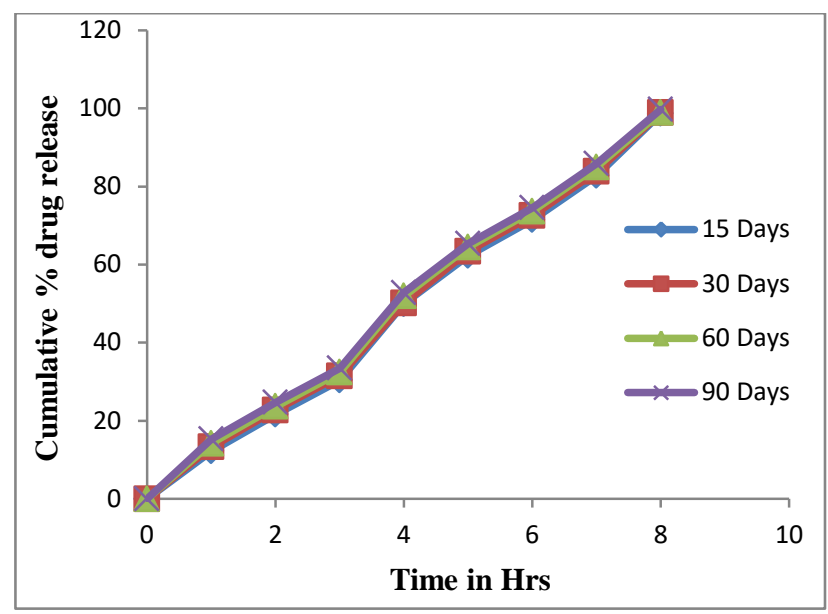

Figure 9: In vitro studies of formulation LNSF4 Acceleration stability studies

\section{CONCLUSION}

From the experimental result, it might be complete so the evaluation of your suspension, unconcealed that the following parameters for the customized formulation LNSF4 are as follows saturation solubility, \% Drug content $97 \pm 2.5 \%$, average particle size $532.2 \mathrm{~nm}$, polydispersity index 0.283 , Zeta potential $-4.79 \mathrm{mv}$. The poloxamer-188 used a polymer in LNSF4 has shown effective cumulative drug waiver equal 8 hours in comparison to any other formulations. The Release order kinetic study shown in the LNSF4 revealed that the exponent " $n$ " value is within the limits. It indicated that the release mechanism for LNSF4 may be a diffusion mechanism followed by the non fickian transport so the LNSF4 was chosen as first formulation. These are an indication of the stability going from the Nanosuspension. The stability studies indicate for which the Nanosuspension is more stable in acceleration stability studies. From the above studies, it is evident that a promising drug delivery system of the Lamivudine nanosuspensions.

\section{Acknowledgment:}

I would like to thank Principal (Dr. M. Gobinath Sir) of Ratnam Institute of Pharmacy, Pidathapolur (V), Muthukur (M), Nellore-524 346, Andhra Pradesh, India.

\section{Conflict of interest}

No conflict of interest in this study.

\section{Funding support}

No financial support

\section{REFERENCES:}

1. Witika BA, Smith VJ, Walker RB, Quality by Design Optimization of Cold Sonochemical Synthesis of Zidovudine-Lamivudine Nanosuspensions, Pharmaceutics, 2020; 12(4): 367-379. https://doi.org/10.3390/pharmaceutics12040367

2. Chakravarty M, Vora A, Nanotechnology-based antiviral therapeutics. Drug Delivery and Translational Research, 2021; 11(3):748-787. https://doi.org/10.1007/s13346-020-00818-0

3. Mothilal M, Krishna M, chaitanya Teja, Surya SP, Manimaran V, Damodharan N, Formulation and evaluation of naproxeneudragita RS 100 nanosuspension using 32 factorial design,
International Journal of Pharmacy and Pharmaceutical Sciences, 2014; 6(7):449-455.

4. Sakshi Taneja, Satish Shilpi, Kapil Khatri, Formulation and optimization of efavirenz nanosuspensions using the precipitation ultrasonication technique for solubility enhancement, Artificial Cells, Nanomedicine and Biotechnology, 2016; 44(3):978-984.

5. Viswanatha Reddy M, Saravana Kumar K, Ramesh Y, Chanukya Kumar G, Venkateswarlu I, Venkatesh R, Preparation And Evaluation Of Quetiapine Fumarate Microspheres, Journal of Pharmacy Research, 2011; 4(11):4164-4166.

6. Jacob S, Nair A B, Shah J, Emerging role of nanosuspensions in drug delivery systems. Biomaterials Research, 2020; 24(3):1-16 https://doi.org/10.1186/s40824-020-0184-8

7. Alukda D, Sturgis T, Youan BC, Formulation of tenofovir-loaded functionalized solid lipid nanoparticles intended for HIV prevention, Journal of Pharmaceutical Sciences, 2011; 100(8):3345-3356. https://doi.org/10.1002/jps.22529

8. Ahuja BK, Jena SK, Paidi SK, Bagri S, Suresh S. Formulation, Optimization and in Vitro-in Vivo Evaluation of Febuxostat Nanosuspension. International Journal of Pharmaceutics, 2015; 478(2): 540-552. https://doi.org/10.1016/j.ijpharm.2014.12.003

9. Praveen G, Parameswari A, Formulation and In-vitro Evaluation of Moxifloxacin Microspheres Using Natural Polysaccharides. Future Journal of Pharmaceuticals and Health Sciences, 2021; 1(1):24-28.

10. Rajesh B Nawale, Uday A Deokate, Sandhana R Shahi, Pradeep M, Lokhande, Formulation and Characterization of Efavirenz Nanosuspension by QbD approach, Research Journal of Pharmacy and Technology, 2017; 10(9):2960-2972. https://doi.org/10.5958/0974-360X.2017.00525.X

11. Naga Durga Mani Achyath S V, Saibabu CH, Malyadri T, Formulation and Invitro Characterization of Fluvoxamine Loaded Nanoparticles. International Journal of Health Care and Biological Sciences, 2021; 2(2):43-52.

https://doi.org/10.46795/ijhcbs.vi.160

12. Salem H F, Sustained-release progesterone nanosuspension following intramuscular injection in ovariectomized rats. International Journal of Nanomedicine, 2010; 5:943-954. https://doi.org/10.2147/IJN.S12947

13. Muniraja Lakshmi K, Kiran M, Sai Prasanna K, Appa Rao, Formulation and Characterization of Silver Nanoparticles Loaded with Aqueous Extract of Lantana Camara Linn Leaves, Future Journal of Pharmaceuticals and Health Sciences, 2021; 1(2):21-28.

14. Permana A D, McCrudden M T C, Donnelly R F, Enhanced Intradermal Delivery of Nanosuspensions of Antifilariasis Drugs Using Dissolving Microneedles: A Proof of Concept Study, Pharmaceutics, 2019; 11(7):3-22.

https://doi.org/10.3390/pharmaceutics11070346

15. Verma S, Gokhale R, Burgess DJ. Pharmaceutical Nanotechnology A Comparative Study of Top-down and Bottom-up Approaches for the Preparation of Micro / Nanosuspensions. 2009; 380:216222. https://doi.org/10.1016/j.ijpharm.2009.07.005

16. McConnachie LA, Kinman LM, Koehn J, Kraft JC, Lane S, Lee W, Collier AC, Ho RJY. Long-Acting Profile of 4 Drugs in 1 Anti-HIV Nanosuspension in Nonhuman Primates for 5 Weeks After a Single Subcutaneous Injection. Journal of Pharmaceutical Sciences, 2018; 107(7):1787-1790. https://doi.org/10.1016/j.xphs.2018.03.005 